\title{
Putquerurco: Antiguas expresiones rupestres de la provincia de Luya, Amazonas (Perú)
}

\author{
Putquerurco: Ancient rock expressions of the province of Luya, Amazonas \\ (Peru)
}

\author{
Arturo Ruiz Estrada \\ https://orcid.org/0000-0003-0687-2603 \\ Arturo.RE38@qmail.com \\ Investigador Independiente
}

\section{RESUMEN}

Las sociedades precoloniales que habitaron el antiguo territorio peruano de Amazonas nos legaron diversas expresiones culturales en diferentes materiales. Entre estos, destacan los complejos monumentales y numerosos objetos ocultos aún en la maraña vegetal. Se añade también otros elementos como la producción rupestre plasmada en abrigos rocosos distribuidos por los valles que fluyen a los ríos Utcubamba y Marañón, cuyo estudio viene incrementándose paulatinamente. Debido a que el arte rupestre es un medio de expresión sobre las actividades de un grupo social en los diversos momentos de su historia, enfocamos esta vez el conocimiento del sitio de Putquerurco, localizado en la provincia de Luya. Nuestra intención pretende comprender su antigüedad y las implicaciones que revela la iconografía acerca de la vida social y económica de sus productores. Una aproximación cronológica que proponemos se enmarca en el Holoceno Medio cuando en el espacio alto amazónico no se había alcanzado la formación de sociedades complejas.

Palabras clave: Arte Rupestre; Holoceno Medio; Perú, Amazonas; Luya; Putquerurco.

\section{ABSTRACT}

The pre-colonial societies that inhabited the ancient Peruvian territory of Amazonas bequeathed us various cultural expressions in different materials. Among these, the monumental complexes and numerous hidden objects still stand out in the vegetal tangle. Other elements are also added such as the rock production reflected in rocky shelters distributed by the valleys that flow to the Utcubamba and Marañon rivers, whose study has been gradually increasing. Because rock art is a means of expression about the activities of a social group at various times in its history, this time we focus on the knowledge of the Putquerurco site, located in the province of Luya. Our intention is to understand its antiquity and the implications that iconography reveals about the social and economic life of its producers. A chronological approximation that we propose is framed in the Middle Holotocene when the formation of complex societies had not been achieved in the upper Amazon area.

Keywords: Rock art; Middle Holocene; Peru, Amazonas; Luya; Putquerurco.

(C) Los autores. Este artículo es publicado por ISHRA, Revista del Instituto Seminario de Historia Rural Andina de la Facultad de Ciencias Sociales de la Universidad Nacional Mayor de San Marcos. Este es un artículo de acceso abierto, distribuido bajo los términos de la licencia Creative Commons Atribución 4.0 Internacional (CC BY 4.0) [https://creativecommons.org/licenses/by/4.0/deed.es] que permite el uso, distribución y reproducción en cualquier medio, siempre que la obra original sea debidamente citada de su fuente original. 


\section{Introducción}

En los reconocimientos arqueológicos que realizamos en el departamento de Amazonas, exploramos también varios sitios rupestres cercanos a la ciudad de Lamud, provincia de Luya, departamento de Amazonas. Fue en esta circunstancia cuando al estudiar el sitio arqueológico de Putquerurco, cuando advertimos la existencia de un abrigo rocoso con varios grabados, pero también la presencia, en el mismo sitio, de pinturas rupestres. Es, entonces, que abordamos la presencia de este último tipo de evidencia, referido a las pequeñas pictografías rupestres allí existentes. Por tal razón, el propósito de este trabajo se orienta a presentar un importante paradero rupestre cuyas características sugieren una antigüedad milenaria, es decir que anteceden en miles de años a la consolidación de sociedades complejas en la región de Amazonas. Por otra parte, nos proponemos ampliar el conocimiento de este sitio en vista que estudios anteriores no las consideraron significativas. Atribuyéndole ser un producto rupestre de sociedades tardías de la región de Amazonas. Además, merece dar cuenta de su importancia y antigüedad por cuanto constituyen documentos arqueológicos que aportan informaciones gráficas sobre la vida de las antiguas sociedades de la región andino-amazónica.

Existe una serie de publicaciones acerca de la producción rupestre en el departamento de Amazonas cuya lectura permite, en cierta medida, tener un cuadro referencial para la continuidad de las investigaciones sobre este tipo de restos arqueológicos. En el caso de la provincia de Luya observamos que actualmente tales publicaciones han incrementado el conocimiento de tal producción, aunque en el siglo pasado Louis Langlois ya había dado a conocer un sitio, al visitar Puente Utcubamba, donde él observó varias pictografías (Langlois, 1939). Posteriormente, Henry y Paule Reichlen mencionaron grabados en las inmediaciones de Kaclic, esto es, en el sitio de La Pitaya (Reichlen, 1950). Luego, fue Hans Horkheimer quien aportó algunos datos sobre el mismo sitio (Horkheimer, 1959). Corresponde a Newman Aguilar haber puesto en conocimiento varios sitios rupestres en la provincia de Luya entre los cuales señaló el abrigo de Putquerurco, lugar donde él identificó, por primera vez, la existencia de petroglifos y pinturas (Aguilar, 1997). Otro autor que ofreció referencias sobre el arte rupestre nororiental ha sido Ulises Gamonal mediante la revista Facetas (Gamonal, 1981, 1986). Pero fue Klaus Koschmieder quien, al explorar la provincia de Luya, obtuvo importantes resultados, pues reveló buen número de centros de arte rupestre, de modo que, hasta el presente, podemos reconocer a esta provincia como la que posee el mayor número de este tipo de vestigios, a nivel del departamento de Amazonas. (Koschmieder, 2012, 2013).

Para otras provincias, fue Keith Muscutt quien realizó estudios puntuales en la parte sur de este departamento, sector donde identificó los sitios de Osiris y otro en el distrito de Chuquibamba (Muscutt, 1987, 1989). Una publicación, referida a la provincia de Utcubamba dio cuenta de las pinturas de Yamón (Shady y Ruiz, 1987). Un inventario nacional de arte rupestre considera a Putquerurco con algunos detalles del sitio (Hostnig, 2003). El profesor César Olano presentó los resultados de reconocimientos en la zona de Lonya Grande, provincia de Utcubamba con varios sitios de interés rupestre, los cuales fueron declarados como patrimonio cultural de la nación mediante la Ley n. 24881 del 29 de julio de 1988 (Olano, 2005) Mirtha Cruzado, hace más de una década registró también varios sitios en la provincia de Utcubamba y los presentó durante el Simposio realizado en la ciudad de Trujillo (Cruzado, 2006). De otro lado, Peter Arana y Horacio Zuta nos ofrecieron algunos datos referidos a la provincia de Luya, aparte de otras correspondientes a Bongará y Chachapoyas (Arana y Zuta, 2009). Anthony Villar publicó tres artículos referidos al sitio de Calpón en la provincia de Utcubamba (Villar, 2019, 2020, 2021) cuyas figuras tienen vinculación con el sitio de Putquerurco. Igualmente, se ha publicado un 
catálogo sobre el arte rupestre de Amazonas auspiciado por la Universidad Nacional Toribio Rodríguez de Mendoza de Chachapoyas (Castillo, 2019). También varias publicaciones dieron a conocer algunos lugares con evidencias rupestres en las provincias de Luya, Chachapoyas y Utcubamba. (Ruiz, 1998, 2007,2008, 2009a ,2009b, 2010a, 2010b, 2013, 2015a, 2015b, 2016)

\section{Metodología}

En esta primera aproximación al estudio de las pinturas de Putquerurco, tuvimos en cuenta, en primer lugar, una revisión bibliográfica que nos permitiera conocer los antecedentes de los estudios realizados en el sitio. Luego, para efectos de la exploración, la realizamos mediante un recorrido de la cuenca del valle por donde discurre el río Jucusbamba, con la finalidad de registrar las condiciones geográficas de la zona para luego efectuar un registro de la distribución de los motivos rupestres en el panel rocoso, actividad que realizamos a simple vista. En esta fase se tomaron fotografías de todos los diseños visibles, como también obtuvimos un promedio de las medidas de las figuras con la finalidad de contrastarlas con las figuras de otros sitios de la región. Una tarea importante fue registrar el contexto ambiental en el que se ubica el sitio con la finalidad de caracterizar sus relaciones dentro del paisaje circundante que nos permitiera vislumbrar las razones adoptadas por quienes ocuparon el abrigo rocoso. En el gabinete aplicamos el programa DStrecht para clarificar la forma de los dibujos y posibles superposiciones de los motivos. Fue importante también cotejar el estilo de los motivos rupestres con otros de la región peruana de Amazonas y otros lugares del espacio andino.

\section{Luya}

Actualmente Luya comprende una provincia del departamento de Amazonas, Perú. Tiene como capital al pueblo de Lamud, en cuyas inmediaciones se localiza justamente el sitio de Putqueruco en el curso del río Jucusbamba. Su territorio comprende un sector altoandino y otro ocupa espacios del margen derecho del río Utcubamba. En tiempos coloniales se lo reconoció como provincia de Luya y Chillao porque incluyó los territorios de la parte alta o Luya y la parte baja o Chillao (Pérez de Astoas, 1996 [1762]). En tiempos preincaicos Luya estuvo poblado por un grupo humano, denominado Hatun Luya, situado entre el margen izquierdo del río Utcubamba y el margen derecho del rio Marañón. Este grupo fue contemporáneo a los grupos de Leymebamba, Cochabamba y Cajamarquilla, localizados en la parte sur del departamento de Amazonas. Se ha sugerido que a estas tres unidades los incas las denominó genéricamente como Chachapoyas, término que fue replicado por los españoles, pese a que este no era conocido en la región del Utcubamba antes de los Incas. Varios manuscritos de tiempos coloniales contienen declaraciones de pobladores nativos, pero en ningún caso estos manifiestan ser de algún pueblo denominado Chachapoyas (Espinoza, 1967; Schjellerup, 2005). Actualmente, algunos autores continúan denominando como Chachapoyas a todos los restos arqueológicos de las provincias de Luya, Utcubamba, y Chachapoyas, a pesar de los resultados que documentan las investigaciones arqueológicas e históricas. Estas investigaciones afirman haber encontrado claras diferencias entre los vestigios registrados en las actuales provincias de Luya y de Chachapoyas. (Guengerich, 2017)

\section{El abrigo de Putquerurco}

El lugar se encuentra próximo a la ciudad de Lamud, capital de la provincia de Luya, departamento de Amazonas, Perú (figura 1). Ocupa una quebrada estrecha marginada por altos flancos rocosos en cuyo fondo discurre el río Jucusbamba, que baja hacia la cuenca del Utcubamba (figura 2). El propio abrigo ocupa el tramo inferior de un alto acantilado, sobre el margen derecho de la quebrada, donde aparece un lienzo vertical que viene a ser el soporte rocoso de arenisca, utilizado 
en tiempos ancestrales para perennizar mensajes grabados y pintados (figura 3). Las medidas del abrigo rocoso alcanzan $26.98 \mathrm{~m}$ de largo con una altura de 15 a $20 \mathrm{~m}$ y una profundidad máxima de $3 \mathrm{~m}$. El espacio utilizado para plasmar las figuras tiene aproximadamente $20 \mathrm{~m}$ de largo con una altura de $5 \mathrm{~m}$. Un muro bajo, hecho de piedras y barro mezclado con paja y pachillas, aparece unido hacia la parte media del piso del cobertizo, cuya altura es de $0.70 \mathrm{~m}$ con un ancho de $0.50 \mathrm{~m}$. Debió ser un pequeño recinto o plataforma cuyos componentes arquitectónicos se han destruido. Todos los motivos rupestres se encuentran a poca distancia del piso. El cual queda a una distancia de $10 \mathrm{~m}$ del lecho del río Jucusbamba.

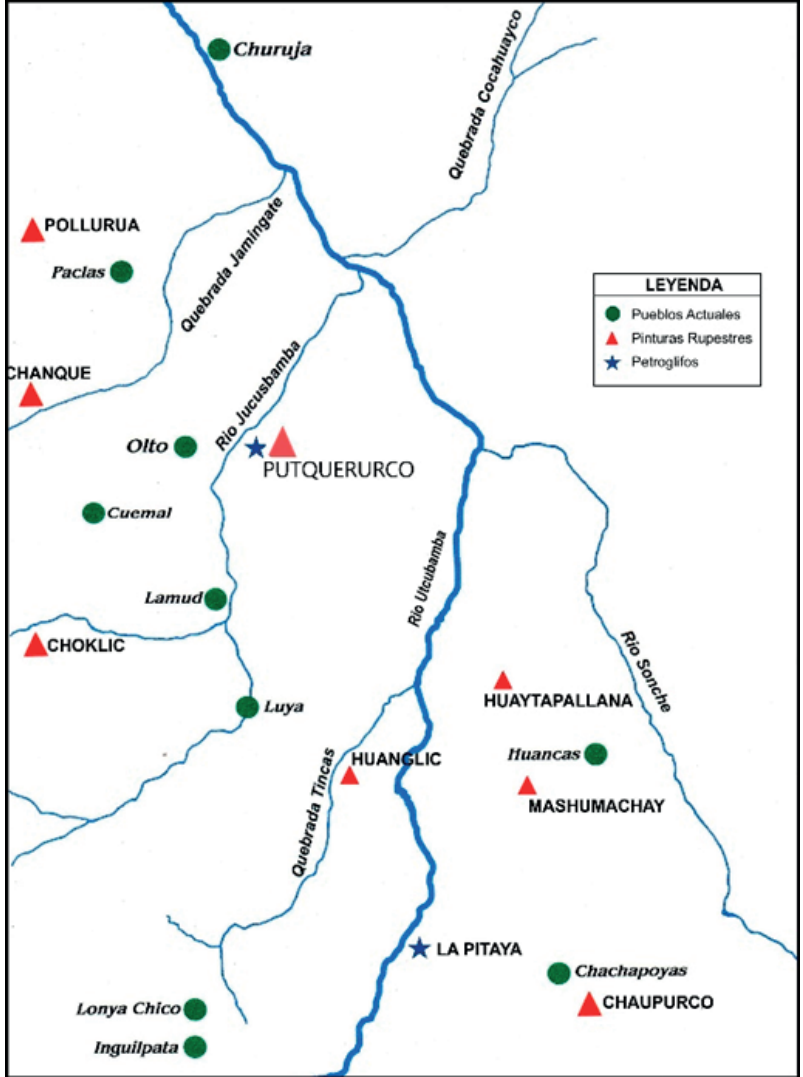

Figura 1. Ubicación del abrigo rocoso de Putquerurco en la cuenca del río Jucusbamba, provincia de Luya, departamento de Amazonas, Perú. (Dibujo: A. Ruiz, 2020)

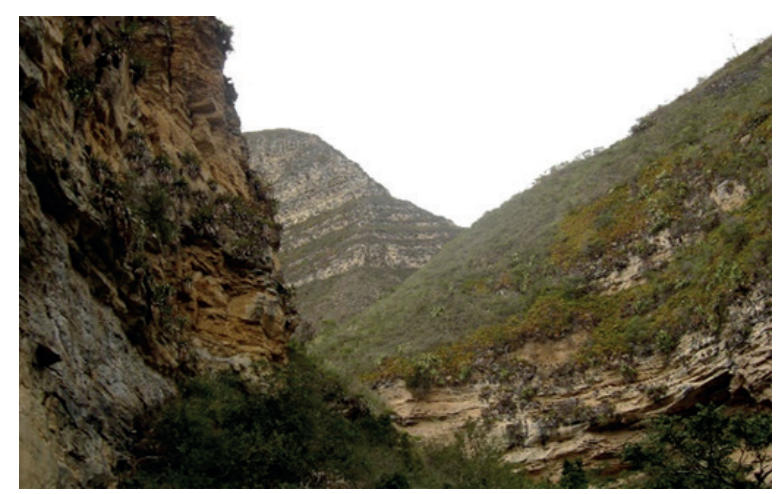

Figura 2. Altos acantilados que marginan la cuenca del rio Jucusbamba donde se localiza el abrigo rocoso de Putquerurco. (Foto: A. Ruiz, 2019)

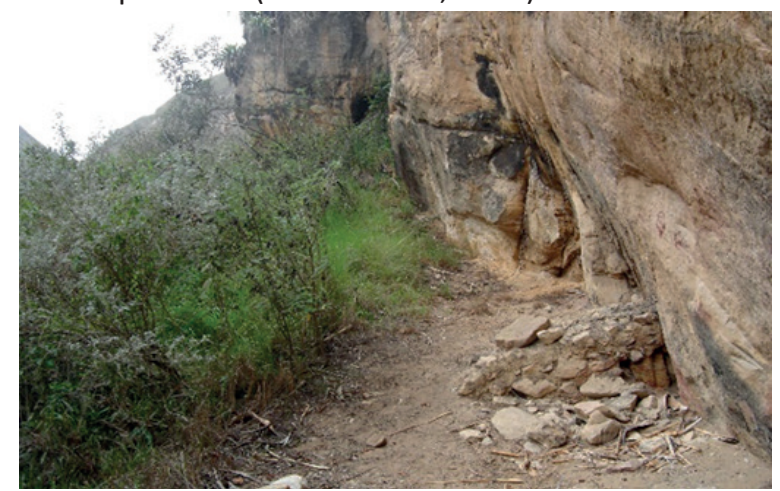

Figura 3. Abrigo rocoso de Putquerurco a cuyo pie se observa un pequeño muro. (Foto: A. Ruiz, 2019)

\section{Los petroglifos}

Los motivos rupestres más visibles están conformados por este tipo de grabados, entre los cuales destacan figuras completas de aspecto antropomorfo, otros solo cefalomorfos, vulvas y algunos de tipo geométrico. Estos petroglifos fueron informados ya hace algunos años en los cuales se dio cuenta del repertorio allí plasmado. (Aguilar, 1997; Koschmieder, 2013)

\section{Las pinturas}

Tal como lo advertimos más arriba, aparte de los motivos rupestres grabados en el sitio de Putquerurco, llama la atención la presencia de varias pinturas distribuidas entre dichos grabados, especialmente hacia el lado izquierdo de la pared. Es decir, no todas las pinturas están agrupadas en un solo conjunto. Algunas figuras casi no son visibles debido al deterioro causado por el 
transcurso del tiempo. El repertorio pictográfico consta de motivos antropomorfos, arboriformes, varios diseños zoomorfos y otros geométricos.

Todas las figuras fueron realizadas a tinta plana para lo cual emplearon un pigmento de color rojo oscuro. Debió haberse utilizado para tal efecto un material ferruginoso u otra sustancia aún no identificada. El tamaño de ellas es pequeño, especialmente los diseños antropomorfos cuyas medidas no exceden los $0.10 \mathrm{~m}$.

Una primera escena, localizada hacia el extremo del lado oeste del reparo rocoso muestra un personaje que al parecer porta un bastón, junto a una figura de aspecto rectangular muy borrosa. (Figuras 4a, 4b)
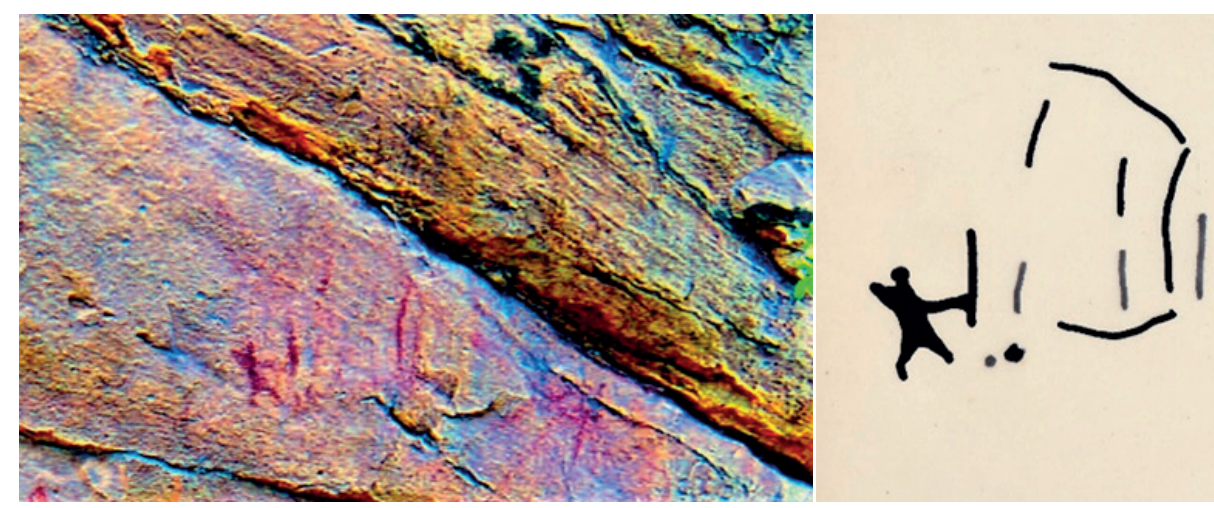

Figura 4a. Foto procesada por DStretch de un personaje Figura 4b. Dibujo basado en la figura anterior. que porta una lanza o bastón junto a una figura rectangular borrosa.

(Foto y dibujo: A. Ruiz, 2019)

Otra escena, ubicada más hacia el lado oriental del lienzo pétreo permite distinguir dos figuras arboriformes con sus respectivos frutos. El árbol del lado derecho muestra, igualmente, sus frutos y un personaje trepado en él. Hacia el lado izquierdo se observa un trazo curvo que parece concluir en un motivo zoomorfo. Junto a este, aparecen cuatro cuadrúpedos cercanos a una figura elíptica con rayas al interior que parece una trampa. Más hacia el centro aparecen cinco antropomorfos en posición frontal, brazos dirigidos hacia abajo y un cuadrúpedo. El árbol del lado derecho muestra, igualmente, sus frutos y un personaje trepado en él. (Figuras 5a y 5b)

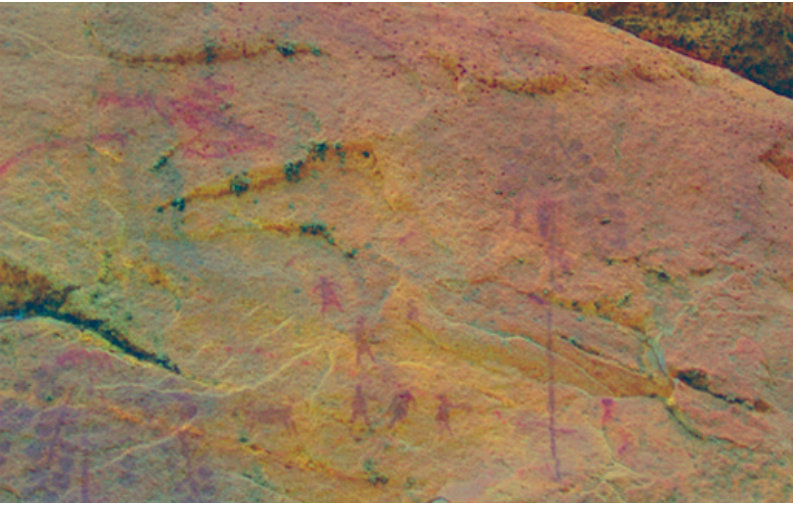

Figura 5a. Foto de escena que muestra a varios cuadrúpedos y una posible trampa. Además, varios personajes en actividad de recolección ente dos figuras arboriformes.

(Foto y dibujo: A. Ruiz, 2019)

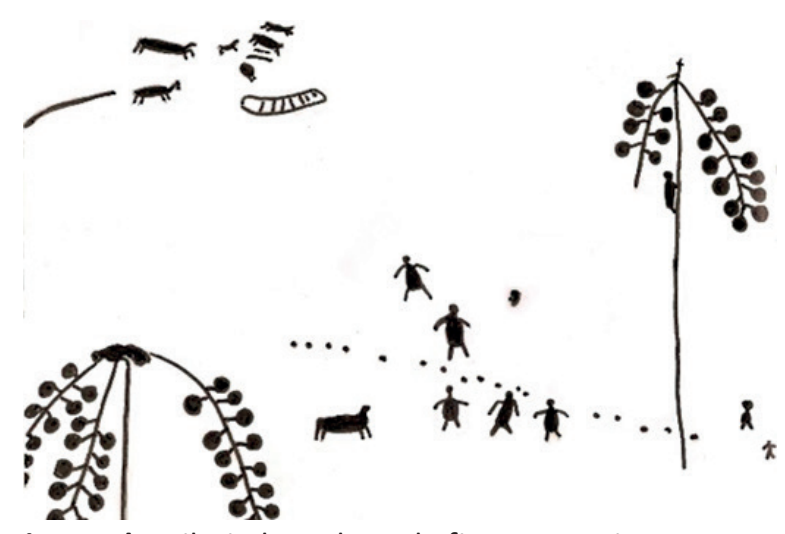

Figura 5b. Dibujo basado en la figura anterior. 
Una tercera escena muestra la figura de un antropomorfo de cuerpo abultado que empuña un lazo, y tiene las piernas abiertas. Bajo este, se inicia una hilera de puntos que corren en forma sinuosa. Sobre esta línea apreciamos otra hilera de cinco figuras antropomorfas con detalles de la cabeza, del cuello, de los brazos doblados hacia abajo y las piernas abiertas. Sus medidas son de 0.08 a $0.09 \mathrm{~m}$. Aparece, también, una mancha y luego otra hilera de puntos que hacen una curva, a unos $0.40 \mathrm{~m}$ de distancia cuya longitud es de $0.50 \mathrm{~m}$. (Figuras 6a, 6b y 6c)

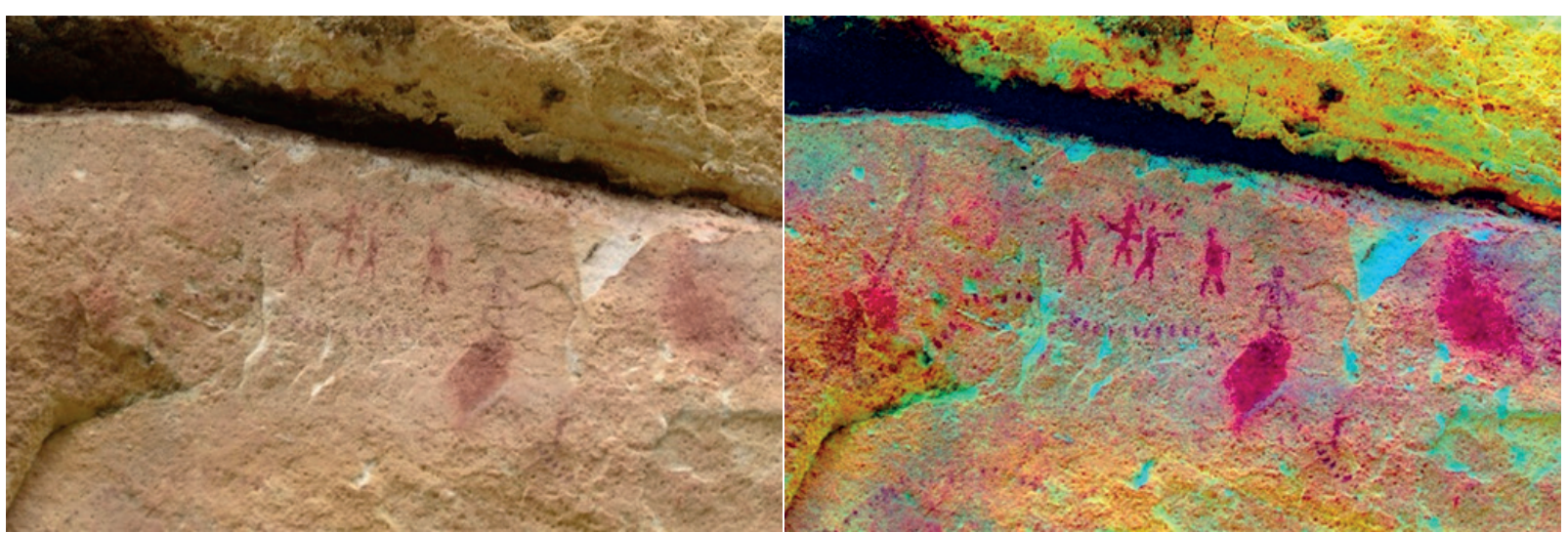

Figura 6a. Foto de una escena de personajes Figura 6b. Fotografía procesada en programa DStretch antropomorfos en actividad entre líneas de puntos de la figura anterior. y manchas. Uno porta al parecer un lazo y otro que empuña un arma.

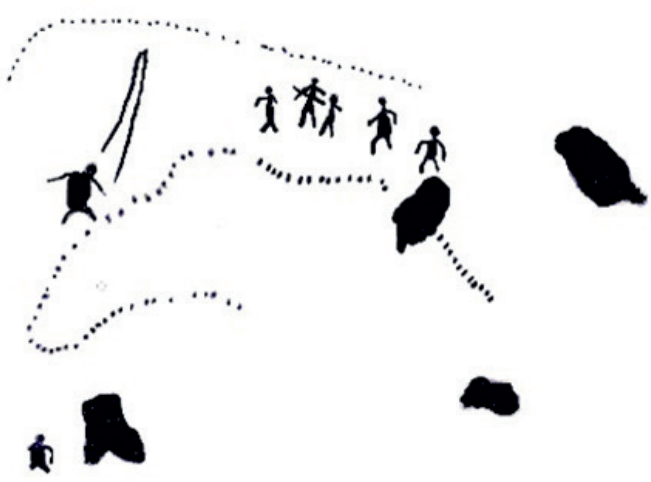

Figura 6c. Dibujo basado en la figura 6b. (Foto y dibujo: A. Ruiz, 2019)

Al extremo oeste aparece una escena de un conjunto con motivos antropomorfos en posición frontal y los brazos levantados que parecen empuñar mazos, y tienen las piernas abiertas. Otros tres, algo borrosas, cierran el conjunto. Sobre estos motivos se ve dos líneas de puntos y una mancha a la derecha (Figuras $7 \mathrm{a}, 7 \mathrm{~b}$ ). Toda esta escena se ubica delante de un petroglifo con figura de ave.

Destaca también entre estas figuras un motivo de mayor tamaño que el resto de figuras, pero distanciado de las figuras pequeñas. Es un dibujo antropomorfo de $0.37 \mathrm{~m}$ de alto por $0.31 \mathrm{de}$ ancho, realizado mediante la técnica del delineado con un pigmento rojo claro. (Figuras 8a, 8b)

Existe también una figura geométrica biconcéntrica cuyo color se muestra similar al resto de motivos pintados. Presenta la forma más o menos rectangular. (Figuras 9a, 9b) 

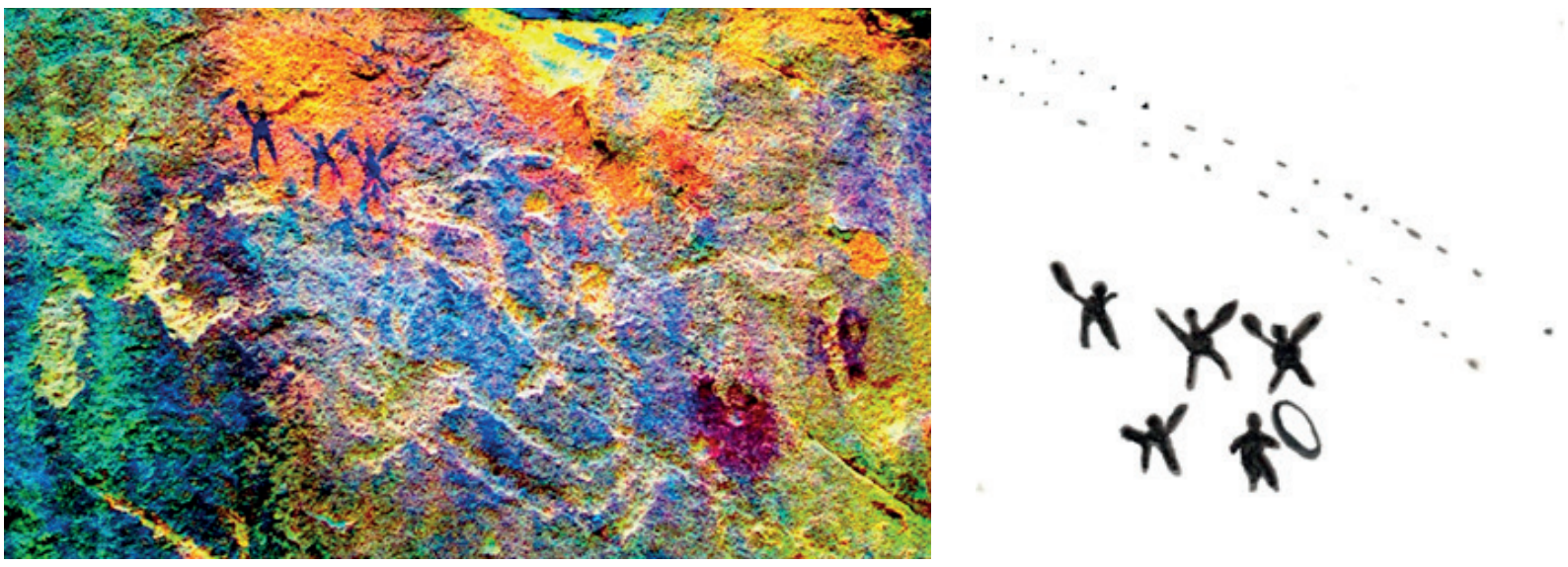

Figura 7a. Fotografía procesada en programa DStrecht de Figura 7b. Dibujo basado en la figura anterior. personajes en pleno movimiento empuñando mazos bajo líneas de puntos.

(Foto y dibujo: A. Ruiz, 2019)
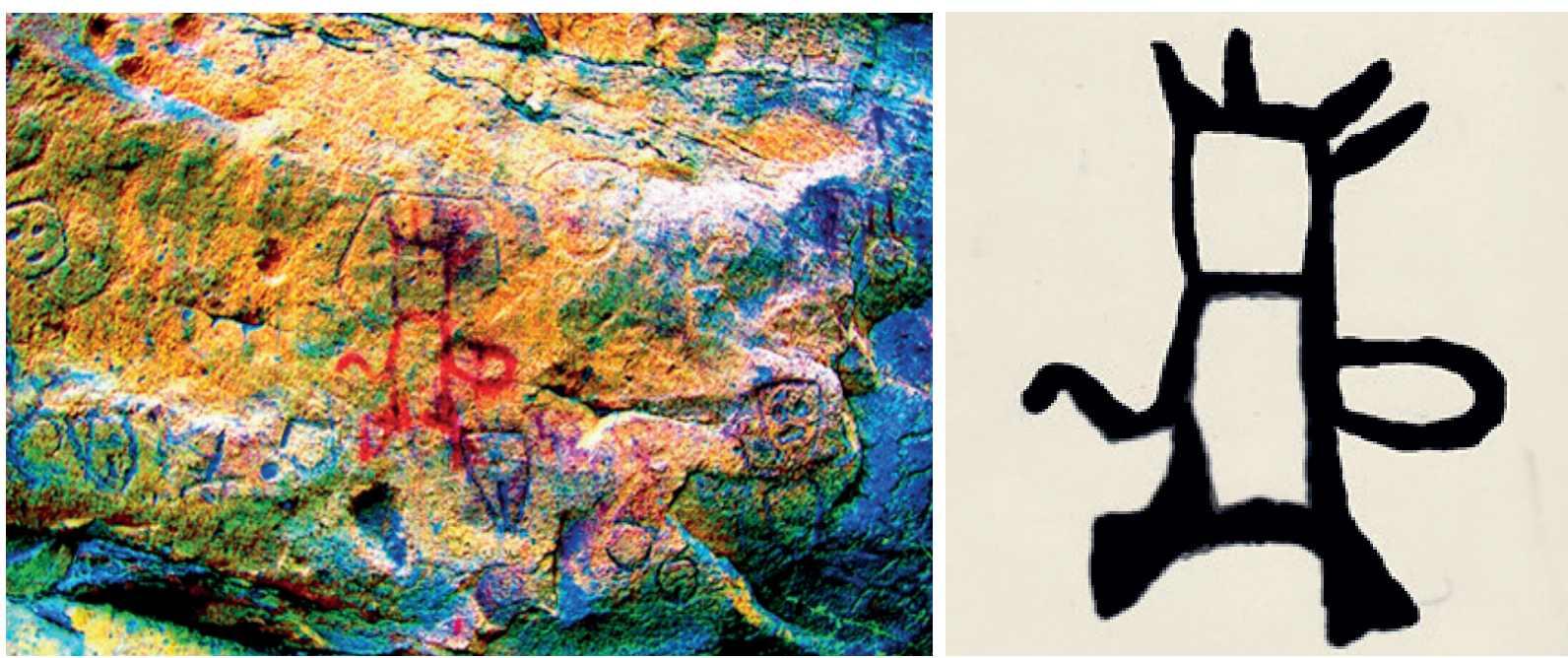

Figura 8a. Fotografía procesada en programa DStrecht de motivo Figura 8b. Dibujo basado en la figura anterior. antropomorfo esquemático de trazo lineal de color rojo claro.

(Foto y dibujo: A. Ruiz, 2019)
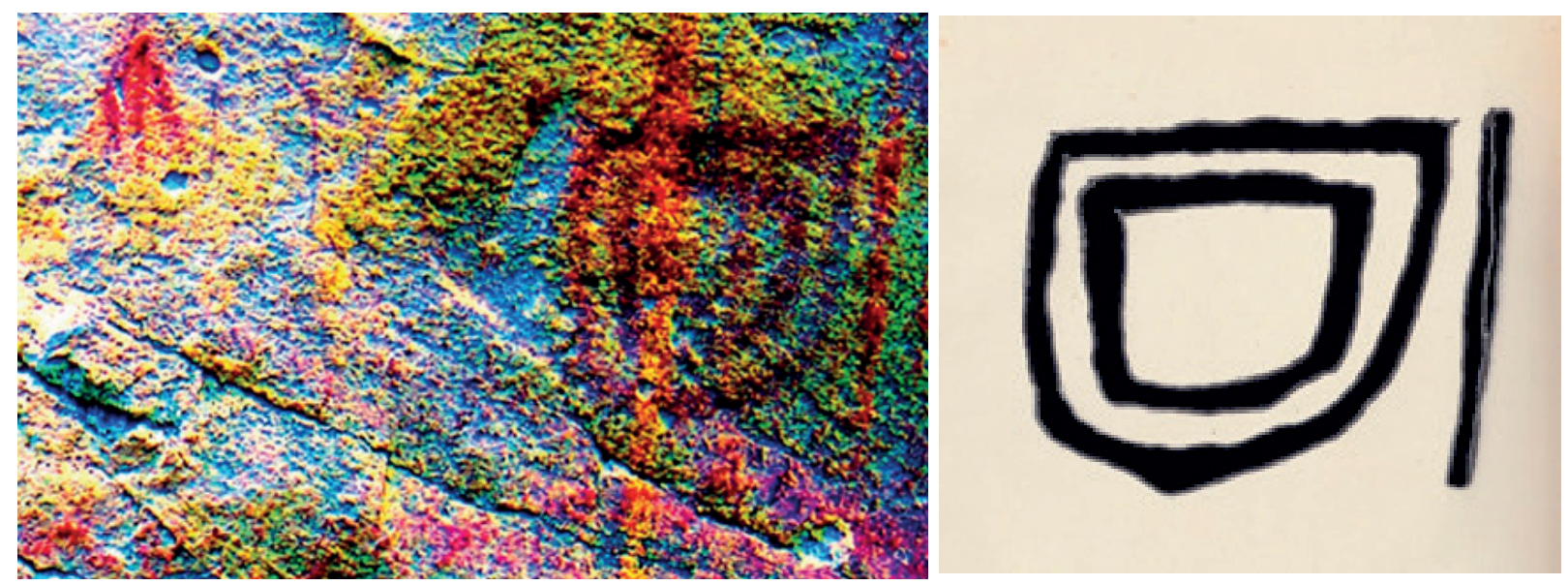

Figura 9a. Fotografía procesada en programa DStretch de una Figura 9b. Dibujo basado en la figura anterior. figura geométrica biconcéntrica mas o menos rectangular.

(Foto y dibujo: A. Ruiz, 2019) 


\section{Estado de conservación}

De modo general, en varios sectores del panel, entre los petroglifos y las pinturas, se han realizado inscripciones modernas que, en cierta manera, han dañado algunos motivos. En cambio, la humedad o las lluvias no lo ha afectado, debido a la inclinación del cobertizo que los protegió. Eso ha permitido un regular estado de conservación. En este sentido, para proteger de nuevos hechos irresponsables, invocamos a las autoridades locales tomar decisiones que eviten su deterioro. Su conservación es una tarea importante por cuanto Putquerurco expresa, una de las primeras manifestaciones gráficas de los remotos pobladores de Lamud y de la provincia de Luya.

\section{Discusiones}

Al presente, no es muy común reconocer en Amazonas la presencia en un solo sitio que exhiba grabados y pinturas. En su mayoría, sólo muestran pinturas o únicamente grabados, pero en el caso de Putquerurco estamos ante un cuadro en el que alternan ambos tipos de figuras. Esta situación adquiere importancia por cuanto revela el permanente interés por quienes insistieron probablemente en utilizarlo para difundir su mensaje, durante diferentes momentos de la historia del sitio.

Las representaciones de pictografías antropomorfas se encuentran en posición frontal con los brazos en diferentes posiciones y las piernas separadas. No tienen mayores detalles anatómicos y ningún adorno complementario, aunque señalan la cabeza, el cuello, y las extremidades. Todas expresan movimiento, e incluso aparece una figura trepada en un árbol. (Figura 5b)

No hay duda que la presencia de los reducidos diseños pintados adquiere particular interés para acercarnos al conocimiento de la historia ancestral de la provincia de Luya y también del departamento de Amazonas. Los rasgos que ellos presentan, en cuanto al estilo, el tamaño, el color utilizado y la actitud en movimiento que los distingue, son detalles que inducen a encontrar parentesco con sitios como los de Yamón y Calpón localizados en la provincia de Utcubamba, en el margen derecho del río Marañón, a 200 km de distancia del sitio de Putquerurco. En estos sitios son frecuentes las figuras de tamaño pequeño a las cuales podemos calificar de micropictografías. Igualmente lo había notado Klaus Koschmieder al explorar Putquerurco cuando afirmó que en este sitio aparecían personajes de miniatura de 3 por $2 \mathrm{~cm}$ (Koschmieder, 2013). Es bastante notorio también la relación con el sitio de Limones, en la vecina provincia de Utcubamba, lugar donde se aprecia una escena narrativa similar (figura 10), si observamos el dibujo de la Fig. 10 elaborada por A. Villar Quintana en base a la foto de César Olano quien identificó este sitio (Villar Quintana, 2020, p. 18; 2021, p. 221). Tal coincidencia nos indica que hubo grupos humanos que ocupaban tanto el valle del Marañón como el del Utucubamba quienes dejaron en estos valles similares expresiones rupestres vinculadas con actividades de recolección. De igual manera, observamos similitudes en cuanto al tamaño de los motivos y el color utilizado rojo oscuro, con las pinturas del sitio de Chaclarragra localizado en la provincia de Lauricocha, departamento de Huánuco (Cardich, 1964) y Toquepala, perteneciente a la provincia de Tacna (Muelle, 1969), lugares donde también se muestran diseños pequeños de color rojo oscuro, aunque existen diferencias por cuanto destacan en éstos las figuras de camélidos principalmente, que no es el caso de Putquerurco. Además, estos sitios tienen una mayor antigüedad. Pero se ha mencionado que en las pinturas de Toquepala se observan «figuritas de hasta $5 \mathrm{~cm}$ los hombres y $10 \mathrm{~cm}$ los animales» (Muelle, 1969, p. 195). Así se aprecia también, si comparamos, por ejemplo, con las pinturas de seres humanos del mismo sitio ilustradas en la figura 8 por Jean Guffroy (Guffroy, 1999, p. 3) y por Rogger Ravines (Ravines, 2010, p. 67), cuyos rasgos generales tienen similitud estilística con las de Putquerurco. Al respecto, debemos señalar que a falta de mayores 
estudios en la región peruana de Amazonas sobre este tipo de manifestaciones rupestres no nos autoricen ser concluyentes en cuanto al tema cronológico. De otro lado, expresamos nuestra sospecha que las pinturas de Putquerurco sugieren un parentesco lejano con los motivos de la tradición Nordeste del Brasil (Martín y Ason, 2000), zona donde aparecen también figuras monocromáticas de tamaño pequeño y, en algunos casos, grupos de figuras asociadas con árboles como suele ocurrir en el presente caso. Si nuestra propuesta se confirmase, podría significar un avance en la comprensión de las vinculaciones de la zona del valle del Utcubamba con las sociedades de las tierras bajas de la amazonia.

Habíamos mencionado más arriba, sobre la presencia de un muro pegado a la pared del abrigo rocoso, lo cual nos sugiere que debió ser parte de un recinto pequeño o plataforma que tal vez estuvo destinado a realizar algún tipo de ceremonia en honor a las figuras o la peña misma, tal vez sacralizada como elementos intermediarios entre quienes peregrinaban al lugar en ciertas temporadas. Un detalle semejante se encuentra también en el centro rupestre de Chanque de la misma provincia de Luya, motivo por el cual nos inclinamos a sostener que dicha estructura pudo tener la misma función. Por otro lado, la poca profundidad del abrigo rocoso de Putquerurco, nos hace pensar, igualmente, que el sitio no fue de uso cuotidiano o permanente, en vista de la estrechez del sitio que no pudo soportar la presencia de un numeroso grupo humano estable. Es decir, tampoco no se puede pensar que tuvo funciones domésticas.

Las pinturas son casi exclusivamente de personajes antropomorfos con la característica de ser bastante pequeños, situación que permite considerarlas como posiblemente más antiguas que los grabados. Algunos grabados se superponen a las pinturas. En el caso de un motivo pintado en color rojo claro (Figura 8a), distinto al resto y de mayor tamaño que estos, puede tratarse de una pintura más tardía, realizada ya en tiempos del Período Intermedio Tardío.

Debemos anotar que se han encontrado restos culturales en la región de ceja de selva comprendida entre Pataz y las vertientes que bajan a la cuenca del Huallaga que testimonian la presencia humana bastante antigua. Exploraciones realizadas por esta zona ya advirtieron, hace algunos años, esa situación, cuando se afirmó que varias excavaciones revelaron secuencias precerámicas y cerámicas (Lennon, Church y Cornejo, 1989). De igual manera, las investigaciones de Warren Church, practicadas en la cueva de Manachaqui, al sur de la provincia de Chachapoyas, pusieron en evidencia ocupaciones humas que datan entre 10350 a 10270 antes del presente (Church, 2004). Estos fechados indican que la presencia humana es considerable para la región peruana de Amazonas y, si bien no se ha revelado aún restos con dicha antigüedad en la provincia de Luya, no se descarta que grupos humanos contemporáneos hayan frecuentado esta provincia. Es posible entonces que gentes de esos tiempos, pudieran haber dejado sus huellas en el arte rupestre de la provincia de Luya. En una publicación anterior se ha considerado que las figuras rupestres de Putquerurco corresponden a la llamada cultura de los Chachapoyas, vigente durante el Período Intermedio Tardío, entre los silos X al XV d.C. (Koschmieder, 2013). Sin embargo, nuestra propuesta, para el caso de las pinturas de Putquerurco, sostiene que dichas figuras tienen una mayor antigüedad y es posible asignarlas con prudencia bajo una cronología tentativa y relativa de 4000 a. C. No obstante, anotamos que investigaciones posteriores podrán confirmar o definir con mayor precisión esta propuesta, cuando se intensifiquen las exploraciones y excavaciones en la provincia de Luya y en torno al sitio de Putquerurco. Comprendemos que obtener un fechado más certero requiere de mayores estudios cuya realización queda aún pendiente.

Al presente, no encontramos semejanzas con pinturas de la sierra central o sur del Perú, donde son frecuentes las pinturas de camélidos de grandes dimensiones, pero es posible que existan sitios con similares expresiones aun cuando carecemos de informaciones para poder 
contrastarlos. Distan también de sitios rupestres más tardíos de Amazonas, por cuanto en estos, las figuras adquieren mayores dimensiones y expresan otro tipo de motivos, además de las clásicas figuras antropomorfas o zoomorfas, también figuras geométricas de diferentes colores. El hecho de haber plasmado en Putquerurco, escenas narrativas que incluyen figuras con la representación antropomorfa en plena actividad, junto a motivos zoomorfos y arboriformes puede indicarnos que sus autores graficaron dichas escenas relacionadas a la búsqueda o abastecimiento de alimentos para la subsistencia. Debemos añadir que en tiempos coloniales se registró que una huaca de uno de los pueblos de la «Provincia de Chachapoyas», era nada menos que un árbol denominado: «Pozan, guaca de los dichos Chachapoyas del ayllo coyllac, es un árbol sobre un cerro junto al pueblo de coyallap» (Albornoz, ca. s. XVI, p. 33). Si bien este dato fue dado a conocer a fines del siglo XVI, resulta sugerente que se haya recogido tal información referida a que algún tipo de árbol pudo ser una hierofanía superviviente de lejanos tiempos cuando aquellos pintores arcaicos de Putquerurco los representaron justamente en territorio de la antigua provincia de Luya. Pues la cita indica al ayllo de nombre Coyllac, donde en un cerro adyacente al pueblo de Coyallap estaba la huaca. Ambos términos Coyllac y Coyallap fueron tal vez sonidos mal transcritos por quien los escribió en castellano, lo cual nos hace sospechar que tal vez se refería al actual Kuélap, también localizado en la provincia de Luya. Por otro lado debemos añadir que la gráfica rupestre de Putquerurco permite señalar cierto parecido con las figuras del arte rupestre levantino de España, sin que ello signifique contemporaneidad o contacto entre áreas tan distantes. Las figuras tan pequeñas y en movimiento recuerdan tal similitud, tal como también se había sospechado para figuras similares de Toquepala (Muelle, 1969). De la misma manera, parece que en tiempos del Holoceno en algunas regiones, las figuras rupestres tendían a ser de pequeño tamaño, tal como se contempla, también, en el arte rupestre de Sumbay de la provincia de Arequipa, donde pese a haber figuras más bien de color blanco, sus medidas tienen un largo de $0.10 \mathrm{~m}$ y 0.35 m. de largo por 0.07 m. y 0.17 de altura (Hostnig, 2003). Cabe indicar aquí que en el Antiguo Perú existieron diversas culturas y, en consecuencia, cada una tuvo su propia tradición expresiva mediante el arte rupestre desde tiempos del período Precerámico.

En vista de la poca distancia entre el piso del abrigo y las pinturas, colegimos que sus realizadores no utilizaron soportes para pintarlas, pues simplemente los habrían ejecutado en posición erguida. De igual manera, no existe indicio de haberse realizado reuniones en el sitio con gran número de personas o que hayan permanecido por largas temporadas. Esta condición sugiere ser un lugar de visita transitoria por haberla considerado probablemente como un lugar sagrado. No está demás anotar que un acantilado cercano, que antecede al sitio, exhibe varios sarcófagos prendidos en grietas de naturaleza caliza.

Finalmente, se observa que los petroglifos, en varios casos, se ejecutaron sobre los dibujos pintados, lo cual nos permite opinar que estos grabados fueron de realización posterior y cuya presencia se debió a que el sitio ya era un lugar considerado importante por grupos que los antecedieron. En relación a otros sitios con pinturas de la provincia de Luya, las de Putquerurco serían las más antiguas conocidas hasta el presente. Por ello no es posible considerarlas como pertenecientes a la sociedad Chachapoya, la cual ha sido señalada como correspondiente al Período Intermedio Tardío, sino a una etapa muy anterior cuando estuvieron vigentes los ancestrales luyanos del período Precerámico.

\section{Conclusiones}

Existen claras afinidades estilísticas entre el arte rupestre de la cuenca del río Marañón y la del Utcubamba. Ellos, deben representar a grupos humanos que ocupaban dichas áreas durante una misma época. 
De acuerdo a los datos expuestos se prueba la existencia de un arte rupestre de características peculiares que lo distingue de otros centros rupestres de Amazonas, donde las imágenes revelan ser de mayores dimensiones y de diferentes colores. Además, muestran una monocromía, el ocre rojo, que puede ser el inicio de una de las tradiciones de pinturas con este color a lo largo de la historia regional de la amazonia andina.

Según las observaciones realizadas las semejanzas de las pictografías de Putquerurco con otras áreas rupestres como Lauricocha y Toquepala, en cuanto a los detalles del reducido tamaño de las pictografías, como por el pigmento rojo oscuro utilizado y el aspecto narrativo de las imágenes insinúa un rasgo común en dichas áreas, pese a que las de Lauricocha y Toquepala revelan mayor antigüedad. Lo que sí es evidente es la clara relación con los sitios rupestres de Lonya, Calpón, Limones y Yamón, de la provincia de Utcubamba. Por ello, en términos generales, consideramos que las pinturas de Putquerurco pueden alcanzar una antigüedad a nivel del Holoceno Medio en el territorio andino-amazónico.

Un rasgo que unifica a las áreas rupestres mencionadas es que en ellas se presentan en su mayor parte figuras con dimensiones reducidas y de matiz monocromático, aspecto que difiere del arte parietal de otras localidades de la misma región en las que son frecuentes las pinturas de mayores dimensiones, atribuidas, por lo general, a tiempos posteriores al Holoceno.

La posición que muestran las figuras sugiere que ellas están relacionadas con actividades de la vida cotidiana vinculadas a la búsqueda de especies para su consumo. De ahí la presencia de vegetales con sus frutos y de los motivos zoomorfos como la simbolización de sus preocupaciones vitales.

\section{Referencias}

Aguilar Torres, N. (1997). El arte rupestre de Putquerurco, departamento de Amazonas. Unay Runa. Revista de Ciencias Sociales, (2), 14-19.

Albornoz, C. (1967). Instrucción para descubrir todas las huacas del Pirú y sus camayos y Haciendas. Journal de la Societé des Americanistes, 56(1), 17-39.

Arana Tuesta, P. M. y Zuta Chamoli, H. (2009). Arte Rupestre en la Región Amazonas. Lima: s/e.

Church, W. (2004). Manachaqui: Buscando las raíces de los Chachapoyas. Sian. Revista Arqueológica, 9(15), 4-5.

Cardich, A. (1964). Lauricocha. Studia Praehistorica III. Fundamentos para una Prehistoria de los Andes Centrales. Buenos Aires. Centro Argentino de Estudios Prehistóricos.

Castillo Benítez, D. S. (2019). Arte Rupestre en la Región Amazonas. Chachapoyas: Universidad Nacional Toribio Rodríguez de Mendoza e INAAK.

Cruzado Paredes M. (2006). Pinturas Rupestres en los afluentes del Rio Marañón, provincia de Utcubamba y Chota, Arte Rupestre [ponencia inédita]. II Simposio Nacional de Arte Rupestre, Trujillo.

Espinoza Soriano, W. (1967). Los señoríos étnicos de Chachapoyas y la alianza hispano chacha. Histórica, 30, 285-325.

Gamonal, U. (1981). Pinturas Rupestres en el Nor-Oriente. Pakamuros. Revista Nor Oriental, 1(1), 15-22.

Gamonal, U.; Pérez Paredes, V. Hugo y Alarcón Dávila, W. (1986). Arte Rupestre y Mitología Nor-Oriental, Jaén. Visitando el pasado, 1, 19.

Guengerich, A. (2017). La diversidad local frente a la "cultura Chachapoyas" en la arquitectura doméstica. Boletín de Arqueología PUCP, (23), 207-230.

Guffroy, J. (1999). El arte rupestre del Antiguo Perú. Lima: Instituto Francés de Estudios Andinos, Institut de Recherche pour le Développement. 
Horkheimer, H. (1959). Algunas consideraciones acerca de la arqueología en el valle del Utcubamba. En Actas y Trabajos del II Congreso Nacional de Historia del Perú (pp. 71-101). Lima: Centro de Estudios Histórico Militares del Perú.

Hostnig, R. (2003). Arte Rupestre del Perú. Inventario Nacional. Lima: Consejo Nacional de Ciencia y Tecnología.

Koschmieder, K. (2012). Jucusbamba. Investigaciones arqueológicas y motivos Chachapoya en el norte de la Provincia de Luya, Departamento de Amazonas, Perú. Lima: Tarea Gráfica Educativa.

Koschmieder, K. (2013). Arte rupestre en la Provincia de Luya, Departamento de Amazonas. Revista del Museo de Arqueología, Antropología e Historia, (12), 167-206.

Langlois, L. (1939). Utcubamba. Investigaciones arqueológicas en el valle de Utcubamba (Servicio de Traducciones n. ${ }^{\circ}$ 3). Lima: Imprenta del Museo Nacional.

Lennon, T J., Warren B. Church, W.B. y Cornejo G. M. (1989). Investigaciones arqueológicas en el Parque Nacional Río Abiseo, San Martín. Boletín de Lima, 11(62), 43-56.

Martin, G y Ason, I. (2000). El horizonte Nordeste en el arte rupestre de Brasil. Saguntum, (32), 67-76.

Muelle, J. (1969). Las cuevas y pinturas de Toquepala. En Mesa Redonda de Ciencias Prehistóricas y Antropológicas, tomo 2 (pp. 186-196). Lima: Instituto Riva Agüero, Pontificia Universidad Católica del Perú.

Muscutt, K. (1987). A Trophy Head Pictograph from the Peruvian Amazon. En K. Hedges. Rock Art Papers 5, San Diego Museum Papers 23 (pp. 155-160). San Diego: San Diego Museum of Man.

Muscutt, K. (1989). Cueva de Osiris: A Pictograph Site in the Peruvian Amazon. En K. Hedges. Rock Art Papers 5, San Diego Museum Papers 23 (pp. 107-110). San Diego: San Diego Museum of Man.

Olano, C. (2005). Pinturas Rupestres en Lonya Grande [ponencia inédita]. II Simposio Nacional de Arte Rupestre, Trujillo.

Pérez de Astoas, F. (1996) [1762]. Descripción de la Provincia de Luya y Chillaos. Kuélap, Boletín Cultural, (111), $\mathrm{s} / \mathrm{p}$.

Ravines, R. (2010). Sobre las pinturas parietales del paleolítico peruano. Boletín de Lima, 32(162), 51-101.

Reichlen, H, y Reichlen, P. (1950). Recherches Archeologiques dans les Andes Du Haut Utcubamba. Journal de la Societé des Americanistes Nouvelli série, 29, 219-246.

Ruiz Estrada, A. (1998). Centro de Arte Rupestre en Luya. El Torreón, 2(7), s/p.

Ruiz Estrada, A. (2007). Chanque: un santuario de arte rupestre en la región de Amazonas (Perú). En Hostnig, R.; Strecker, M. y J. Guffroy (Eds). Actas del Primer Simposio Nacional de Arte Rupestre (Cusco, Noviembre 2004) (pp. 97-114). Lima: Instituto Francés de Estudios Andinos.

Ruiz Estrada, A. (2008). Los petroglifos de Jamalca, Amazonas (Perú). Arkeos. Revista electrónica de arqueología, 3(9), s/p. https://bit.ly/3q3NFhZ

Ruiz Estrada, A. (2009a) Las Pinturas Rupestre de Choclic. Rupestreweb. https://bit.ly/3mD94MS

Ruiz Estrada, A. (2009b). El Arte Rupestre de Pollurúa en Paclas, Amazonas, Perú. Rupestreweb. https://bit. $1 \mathrm{y} / 3 \mathrm{pZuG} 8 \mathrm{~h}$

Ruiz Estrada, A. (2010a). Huaytapallana: arte rupestre de Chachapoyas. Revista del Instituto de Investigaciones Sociales, 14(24), 53-65.

Ruiz Estrada, A. (2010b). Una obra maestra del Arte Rupestre de Chachapoyas. El Torreón, (abril-mayo), 9.

Ruiz Estrada, A. (2013). El arte rupestre de Chaup-urco en la region de Chachapoyas, Amazonas, Perú. Rupestreweb. https://bit.ly/3mJ3QiN

Ruiz Estrada, A. (2015a). Mashumachay. Expresiones rupestres en la provincia de Chachapooyas. Rupestreweb. https://bit.ly/2ZV0vo3.

Ruiz Estrada, A. (2015b). La Pitaya en el contexto del arte rupestre y la arqueología de Chachapoyas Perú [ponencia inédita]. XIX Internacional Rock Art Conference, Cáceres.

Ruiz Estrada, A. (2016). Arte rupestre en el valle de Sonche. El Torreón, (noviembre-diciembre), s/p. 
Schjellerup, I. (2005). Incas y españoles en la conquista de los Chachapoya. Lima: Instituto Francés de Estudios Andinos, Fondo Editorial de la Pontificia Universidad Católica del Perú.

Shady, R. y Ruiz, A. (1987). Arte Rupestre en Amazonas-Perú. Boletín de Lima, 9(53), 12-13.

Villar Quintana, A. A. (2019). El arte rupestre de Calpón: una historia de 9000 años. El Clarín, 9(1860), s/p.

Villar Quintana, A.A. (2020). Representaciones escénicas en las pinturas rupestres tempranas de Calpón. Boletín de Lima, 40(194), 61-76.

Villar Quintana, A. (2021). Actividades humanas en el arte rupestre temprano del Marañón (UtcubambaAmazonas). Revista Cuadernos de Arte Prehistórico, (11), 266-288.

Presentado: 30/04/2021

Aceptado: 05/06/2021

Publicado online: 27/12/2021 